\title{
Holoprosencefalia. Incidência na cidade de Pelotas
}

\author{
Gilberto de Lima Garcias*, Maria da Graça Martino-Roth**, Tiago Fontana** \\ Estudo Colaborativo Latino-americano de Malformações Congênitas (ECLAMC). Projeto da Universidade Federal de
}

Pelotas e da Universidade Católica de Pelotas, RS.

\section{RESUMO}

Objetivos: enfatizar a importância do diagnóstico precoce da holoprosencefalia, a abordagem dos casos nascidos vivos e o aconselhamento genético oferecido aos pais. Determinar o delineamento epidemiológico da família de cada caso afetado. Detectar a incidência desta malformação durante o período de estudo. Métodos: estudo retrospectivo, através de revisão de prontuários protocolados, com o questionário do Estudo Colaborativo Latino-Americano de Malformações Congênitas (ECLAMC), em todos os hospitais de nível terciário da cidade de Pelotas (RS). Todos os casos foram submetidos à avaliação judiciosa de um médico geneticista. Foi realizada revisão de literatura médica. Resultados: em 13 anos de coleta de dados (janeiro de 1990 a dezembro de 2002) ocorreram seis casos de holoprosencefalia. A incidência foi de 0,8:10.000 nascimentos. Detectamos a ocorrência de diabete gestacional e ingestão de ácido acetilsalicílico em dois casos isolados, associação esta, que já foi documentada na literatura revisada. Conclusão: a holoprosencefalia é uma grave malformação congênita, podendo ser precocemente diagnosticada para o adequado manejo dos casos nascidos vivos, estudo citogenético familiar e planejamento de gestações futuras.

\section{PALAVRAS-CHAVE}

Holoprosencefalia. Epidemiologia da holoprosencefalia.

\section{ABSTRACT}

Holoprosencephaly. Incidence in the city of Pelotas, Rio Grande do Sul, Brazil.

Objectives: emphasize the importance of the precocious diagnosis of this malformation, the management of the born alive cases and the genetic counseling offered to the parents. To determine the epidemiologic delineation of the family of each affected case. To determine the incidence of this malformation during the 13 years period of study. Methods: retrospective study, through revision of medical records following the questionnaire of the ECLAMC (Latin American Collaborative Study of Congenital Malformations) in all the hospitals of tertiary level of the city of Pelotas, Rio Grande do Sul State, Brazil. All the cases had been submitted to the judicious evaluation of a geneticist doctor. Revision of medical literature was carried through. Results: during the 13 years of data collection (January, 1990 to December 2002) covered by this study, six cases of holoprosencephaly were detected. The incidence was of 0.8:10,000 births. We detect the occurrence of gestational diabetes and use of acetylsalicylic acid in two isolated cases which already was registered in revised literature. Conclusion: the holoprosencephaly is a serious congenital malformation, that can be diagnosed precociously for the adjusted handling of the born alive cases, familiar cytogenetic study and planning of future gestations.

\section{KEY-WORDS}

Holoprosencephaly. Edipemiolgy of holoprosencephaly

\section{Introdução}

A holoprosencefalia é uma complexa malformação do sistema nervoso central (SNC), caracterizada pela ausência ou clivagem incompleta do prosencéfalo, freqüentemente associada a anomalias craniofaciais específicas ${ }^{10,26}$. A incidência estimada dessa malformação, entre abortos (40/
100.000), é maior que entre crianças nascidas vivas $(0,8$ $4,8 / 100.000)^{10,17,19}$. Há cerca de 10 anos, diversos estudos com modelos animais têm procurado esclarecer a patogênese desta desordem, que está sendo desvendada apenas recentemente ${ }^{10}$. O diagnóstico geralmente é realizado durante a gestação, já no primeiro trimestre, através da ultra-sonografia (US) 2,9,16,23,24,26. O diagnóstico

*Professor Doutor de Genética na Universidade Católica de Pelotas e Universidade Federal de Pelotas.

**Professora Doutora de Genética na Universidade Católica de Pelotas.

***Acadêmico da Escola de Medicina da Universidade Católica de Pelotas. Bolsista FAPERGS. 
clínico inicia-se pela visualização das malformações externas, sejam elas craniocefálicas ou não. Entre as primeiras incluem-se a encefalocele, hidrocefalia, microcefalia, hipotelorismo, ciclopia, etmocefalia, cebocefalia, ponte nasal baixa, nariz curto, arrinencefalia e incisivo maxilar central único, com o grau de severidade refletindo a gravidade do acometimento cerebral, na maioria dos $\operatorname{casos}^{12}$. Entre as outras alterações citam-se a polidactilia, a sindactilia, o pé torto, as deficiências do diafragma, do fígado, o baço acessório, a onfalocele, a vagina dupla e a má-rotação do intestino. O retardo mental ocorre, virtualmente, em todos os casos, excetuando-se alguns com forma lobar leve ${ }^{14}$.

Aparecem convulsões, às vezes mioclônicas, em cerca de metade dos casos. Diplegia espástica, ataxia e outros defeitos motores são muito freqüentes. O diagnóstico ultra-sonográfico da holoprosencefalia alobar tem sido relatado desde 1984. Os achados desta anomalia incluem a presença de cavidade monoventricular (que pode ser completamente coberta por tecido cerebral ou estender-se posteriormente), ausência de estruturas medianas (como, corpo caloso e foice) e fusão de estruturas (como, o tálamo). As ocorrências na forma semilobar são similares, juntando-se a presença usual de cornos occipitais rudimentares e separação dos lobos occipitais. O maior montante de tecido cerebral, notavelmente nos lobos temporais, é o fator determinante na diferenciação com a forma alobar. É importante ressaltar que não se deve confundir a cavidade monoventricular, característica da holoprosencefalia, com a cavidade do rombencéfalo primitivo na grávida. Esta estrutura pode ser reconhecida entre oito e 11 semanas de gestação na parte posterior do cérebro e mede cerca de 2 a $4 \mathrm{~mm}$. Na holoprosencefalia, a cavidade pode ser visualizada na parte anterior do crânio fetal. A presença de anomalias fetais faciais pode ser extremamente proveitosa na discriminação entre desenvolvimento cerebral normal e anormal. A investigação da possível presença de anomalias cromossômicas associadas pode ser realizada através de amniocentese.

$\mathrm{O}$ risco de recorrência da holoprosencefalia, nos casos cromossomicamente normais, tem sido estimada em $6 \%$. Já, os casos relatados na literatura, apresentando herança familiar autossômica, seja recessiva ou dominante, registram risco de recorrência de 50\% e 25\%, respectivamente. Quando ocorre aneuploidia associada e a trissomia já foi determinada, o risco é menor que $1 \%$, se a anomalia cromossômica envolver translocação e um dos pais for portador da translocação, o risco é maior $(10 \%)^{18,26}$.

O objetivo dos autores, com o presente estudo, é determinar a incidência dessa malformação na população estudada, enfatizar a importância do diagnóstico precoce, para a adequada conduta dos casos nascidos vivos e oferecer aconselhamento genético familiar. E, através do delineamento epidemiológico da família de cada caso afetado, investigar patologias ou condições maternas que possam estar associadas com a etiologia dessa malformação.

\section{Metodologia}

Foi realizado estudo retrospectivo, através de revisão de prontuários protocolados com o questionário do ECLAMC, em todos os hospitais de nível terciário da cidade de Pelotas (RS), durante o período de 13 anos (de 1 de janeiro de 1990 a 31 de dezembro de 2002). Todos os casos foram submetidos à avaliação judiciosa de um médico geneticista. Foi realizada revisão de literatura médica, através do banco de dados do ECLAMC foi possível quantificar o número de nativivos, natimortos e de malformações.

\section{Estudo dos casos}

\section{Caso 1}

DHS, 39 anos, quarta gestação, três filhos normais. No segundo trimestre de gestação, foi diagnosticada com infecção do trato urinário, a qual foi tratada com nitrofurantoína; não apresentava doenças crônicas. Fez uso de complexo vitamínico $\mathrm{B}$, sulfato ferroso e alfa metildopa, durante o período pré-natal. Não apresentava antecedentes de aborto.

O recém-nascido $(\mathrm{RN})$ de parto cesárea, do sexo masculino, com apresentação cefálica, pesava 1.980 gramas. Apresentava holoprosencefalia, lábio leporino medial com fenda palatina, hipoplasia da cartilagem nasal, microcefalia e fusão dos hemisférios cerebrais.

\section{Caso 2}

MCRF, 31 anos, segunda gestação, primeiro filho normal, com segundo grau completo, pai com segundo grau incompleto. Ambos trabalhando como executivos, descendentes de europeu, latino e negro, não-consangüíneos. No primeiro trimestre de gestação, apresentou quadro de anemia tratado com fumarato ferroso e quadro de cefaléia tratado com dipirona sódica. Fez uso de complexo vitamínico. Não apresentava doenças crônicas. Realizou dez consultas pré-natais e diagnóstico presuntivo, através de duas ultra-sonografias obstétricas, de probóscide e ciclopia. 
O natimorto, extraído por cesárea, era do sexo masculino, pesava 650 gramas. Apresentava probóscide, ciclopia, holoprosencefalia, estenose hipertrófica do piloro, anoftalmia, polidactilia bilateral nas mãos, junto ao quinto dedo, com base séssil, implantado na falange proximal.

\section{Caso 3}

TLG, 30 anos, segunda gestação, primeiro filho normal, com primeiro grau incompleto e trabalhadora do lar. Pai com primeiro grau completo e exercendo ocupação não qualificada. Descendentes de nativos brasileiros, não apresentam consangüinidade. A mãe relatou não ser portadora de doenças crônicas e não apresentou patologias durante o período pré-natal. Não fez uso de medicamentos.

RN de parto normal, masculino, apresentação cefálica, pesava 2.720 gramas. Apresentava holoprosencefalia.

\section{Caso 4}

KAOS, 25 anos, terceira gestação, dois filhos normais, com primeiro grau incompleto e trabalhadora do lar. Pai com primeiro grau incompleto e empregado. Descendentes de europeus, latinos e negros, não apresentavam consangüinidade. Realizou 12 consultas pré-natais e não fez ultra-sonografia obstétrica. Apresentou cefaléia no primeiro trimestre de gestação, tratada com ácido acetilsalicílico. Não apresentou doenças crônicas.

O RN de cesárea, masculino, pesando 4.050 gramas, teve diagnóstico sindrômico estabelecido no período neonatal e recebeu alta hospitalar vivo. Apresentava holoprosencefalia, estenose hipertrófica de piloro e anoftalmia.

\section{Caso 5}

EP, 24 anos, terceira gestação, dois filhos normais, sem escolaridade, mas lê e é trabalhadora do lar. Pai com primeiro grau incompleto e ocupação não qualificada. Descendentes de negros e nativos brasileiros, não são consangüíneos. Realizou quatro consultas pré-natais, não fez ultra-sonografia obstétrica. No primeiro trimestre de gestação, apresentou quadro de infecção do trato urinário tratada com ampicilina. No segundo e terceiro trimestres de gestação, apresentou anemia tratada com sulfato ferroso. Não apresentou patologias crônicas.

RN de parto espontâneo, do sexo feminino, pesando 2.730 gramas, teve o diagnóstico sindrômico firmado no período neonatal. Apresentava holoprosencefalia.

\section{Caso 6}

LOM, 25 anos, segunda gestação, primeiro filho normal, com segundo grau incompleto e trabalhadora do lar. Pai com segundo grau completo e ocupação qualificada. Descendentes de nativos brasileiros, não apresentavam consangüinidade. Apresenta história familiar de polidactilia. Realizou 11 consultas pré-natais e o diagnóstico presuntivo de holoprosencefalia foi feito através de três ultra-sonografias. Teve anemia nos dois primeiros trimestres de gestação tratada com sulfato ferroso. No terceiro trimestre, teve quadro de diabete gestacional. No segundo e terceiro trimestres de gestação, apresentou cefaléia, tratada com paracetamol. Não apresentou doenças crônicas.

O RN de cesárea, feminino, pesando 2.850 gramas, apresentava holoprosencefalia.

\section{Resultados}

Foram avaliados cerca de 71.500 nascimentos; destes $1,37 \%$ tinham alguma malformação congênita, dos quais $15,8 \%$ apresentaram defeitos do tubo neural. A idade média das gestantes, dos conceptos com holoprosencefalia, foi de 29 anos, variando de 24 a 39 anos. Dos seis produtos de concepção, cinco nativivos e um natimorto; quatro do sexo masculino e dois do sexo feminino; quatro nascidos à cesárea e dois de parto espontâneo; o peso médio foi de 2.496,6 gramas, sendo que o menor tinha 650 gramas e o maior com 4.050 gramas. A média de gestações das mães foi de 2,6. Apenas uma mãe e um pai (não-cônjuges) tinham segundo grau completo. Apenas uma mãe e um pai (cônjuges) referiram-se como sendo profissionais executivos, sendo as demais gestantes trabalhadoras do lar. A incidência de holoprosencefalia entre todos os nascimentos foi de 0,8:10.000.

\section{Discussão}

A holoprosencefalia representa a maior malformação cerebral, exibindo como achados característicos a presença de ventrículo telencefálico único e a continuidade dos hemisférios cerebrais através da linha média ${ }^{10}$.

A incidência estimada entre abortos espontâneos (40/100.000) é maior que entre crianças nascidas vivas (0,8 a 4,8/100.000).

Vários métodos de classificação das anomalias do SNC foram desenvolvidos, sendo que a mais freqüentemente usada baseia-se em dois critérios: (a) presença ou ausência de fissura mediana separando os dois hemisférios cerebrais; e (b) extensão da fissura. Desse modo, a forma alobar é a mais severa e a mais comumente associada a anomalias graves, como, ciclopia, 
etmocefalia e cebocefalia; a forma semilobar é intermediária e a forma lobar a menos severa ${ }^{8,15,18}$.

Além do SNC, defeitos craniofaciais específicos (mais constantemente) e sistêmicos podem estar associados à holoprosencefalia e, juntos, constituem a seqüência ou síndrome da holoprosencefalia ${ }^{10,15,18}$. Conforme a extensão, as anomalias craniofaciais variam das mais graves (por exemplo, a ciclopia) às mais brandas (por exemplo, o incisivo maxilar medial único), podendo-se afirmar que, na maioria dos casos, a severidade da lesão facial é capaz de predizer o grau de acometimento do $\mathrm{SNC}^{5,6,10}$.

Diversos fatores ambientais e maternos têm sido associados à seqüência da holoprosencefalia, sendo o diabete materno o mais reconhecido ${ }^{1,10}$. O consumo gestacional de etanol, salicilatos, contraceptivos, quinino, ácido retinóico e cortisona são registrados em vários casos. Outros fatores incluem a exposição a radiações e infecções pré-natais, como citomegalovirose, rubéola e toxoplasmose ${ }^{3,13}$.

Um dos mais importantes teratógenos relacionados com a patogênese da holoprosencefalia foi descoberto em meados de 1960, quando se observou que ovelhas prenhas, alimentando-se da planta Veratrum californicum, originavam prole com ciclopia. Estudos seguintes apontaram a ciclopamina como o agente causador da anomalia. Revelou-se, recentemente, que o mecanismo patogenético, através do qual esse alcalóide exerce seu efeito, está ligado à proteína Sonic Hedgehog (SHH), produzida pelo seu gene SHH, responsável pela indução embriológica de determinadas células (neuroblastos) em sítios cerebrais específicos ${ }^{10}$.

Acredita-se que, além dos casos resultantes de exposição a teratógenos, a maioria dos remanescentes apresenta etiologia genética, pois cerca de $25 \%$ dos pacientes com holoprosencefalia mostram associação com uma síndrome reconhecida. Desse modo, a avaliação do feto, lactente ou criança com esta malformação deve incluir uma investigação completa de outras anomalias sistêmicas. As síndromes documentadas na literatura, e que podem incluir a holoprosencefalia como um de seus componentes, são: pseudotrissomia 13, Smith-Lemli-Opitz, Pallister-Hall, Meckel-Gruber, velocardiofacial, Genoa, Lambotte, Martin e Steinfeld.

Cerca de $25 \%$ a $45 \%$ das crianças nascidas vivas com holoprosencefalia têm anomalia cromossômica não-randomizada, predominando a trissomia do 13; por outro lado, acima de 70\% das crianças com trissomia 13 são acometidas pela holoprosencefalia ${ }^{10,17}$.

Baseados em rearranjos citogenéticos não-randomizados, estudos comprovaram a existência de no mínimo 12 loci, em 11 cromossomos, contendo genes potencialmente envolvidos na patogênese da holoprosencefalia, com quatro deles denominando-se HPEl (21q22.3), HPE2 (2p21), HPE3 (7q36) e HPE4 (18p). Há pouco tempo, conseguiu-se mapear um gene SHH como pertencendo a uma região restrita do locus HPE3. Seguiram-se diversos estudos envolvendo relatos de pacientes e experiências com modelos animais, concluindo que mutações no gene SHH eram capazes de provocar holoprosencefalia. Nesses modelos, as mutações seriam provocadas pela ciclopamina, não se encontrando uma causa correspondente no homem. Além disso, é importante lembrar que vários casos de holoprosencefalia são observados em pacientes sem anomalias cromossômicas, indicando a possibilidade da presença de genes na etiologia da doença ${ }^{10,20}$.

Os mecanismos relacionados com a patogênese da holoprosencefalia envolvem conhecimentos elementares em neuroembriologia. Os clássicos experimentos de Spemann e Mangold demonstraram que o tubo neural poderia ser induzido a partir de uma pequena região de tecido embrionário ${ }^{10,21}$. No sítio da indução, um processo organizado de movimento de células (os neuroblastos) resulta na formação de um feixe primitivo, denominado notocorda. Os movimentos de migração neuronal, freqüentemente por longas distâncias, constituem uma das etapas fundamentais na evolução embriológica cerebral, uma vez que, poucos, ou alguns, neurônios no cérebro humano maduro estão localizados no mesmo sítio, a partir do qual se diferenciarão. Os neuroblastos executam esse processo de forma precisa e ordenada, guiados por células gliais fetais especializadas, com a finalidade de estabelecer uma relação tridimensional e circuitos sinápticos com outros neurônios. Os sinais mediadores da migração neuroblástica são incompletamente compreendidos e o mecanismo desses movimentos é incerto.

Sabe-se que a notocorda induz o revestimento ectodérmico a tornar-se o tubo neural ventral ${ }^{10,22}$. Essa indução é mediada através da proteína SHH. Ela é primeiramente expressada pela notocorda, a partir do seu gene SHH, induzindo a linha média da lâmina de revestimento neural a tornar-se uma região mais especializada, a lâmina do assoalho. As células dessa região são as primeiras células neuroectodérmicas a se diferenciarem, expressando a proteína SHH que leva à indução de vários fatores de transcrição nas colunas ventrais adjacentes. Estas, por sua vez, originam diversas classes de neurônios motores, cada qual dependente da expressão de um fator de transcrição específico, incluindo Wnt-l e gene Hox. O desenvolvimento do tubo neural dorsal parece ser regulado por moléculas denominadas proteínas ósseas morfogenéticas (BMP) e proteínas $\mathrm{Wnt}^{10,14}$.

De maneira similar ao que acontece nas regiões caudais, a proteína SHH participa do desenvolvimento das regiões mais rostrais do tubo neural, sendo 
expressa em dois domínios específicos do prosencéfalo: inicialmente, nos primórdios hipotalâmicos tuberal e mamilar e, posteriormente, no telencéfalo rostrobasal ${ }^{5,10}$.

Estudos observaram que ratos homozigotos, com SHH mutante, perdem o desenvolvimento do prosencéfalo ventral, resultando em ciclopia e holoprosencefalia; achados semelhantes em peixes-zebra corroboram os resultados obtidos com mamíferos ${ }^{4,10}$. As vias genéticas envolvidas na indução da porção dorsal são bem menos definidas que a ventral e incluem a participação das BMP. Estudos com recombinantes BMP4 e BMP5, localizados ectopicamente no prosencéfalo de embriões de galinhas, resultaram em holoprosencefalia, ciclopia e probócide ${ }^{10}$.

Recentemente, tem sido demonstrada a possível interferência de defeitos na biossíntese de colesterol sobre a via de transcrição da SHH. Em experimentos animais, bloqueadores da biossíntese de colesterol são capazes de provocar ciclopia e, em alguns casos, holoprosencefalia. A síndrome de Smith-Lemli-Opitz origina-se de um defeito na biossíntese de colesterol, resultando em severa hipocolesterolemia e, conseqüentemente, holoprosencefalia. Permanece desconhecido o mecanismo exato da interferência da biossíntese de colesterol sobre a via $\mathrm{SHH}^{7}$.

O achado neuropatológico inicial da holoprosencefalia inclui a diminuição do volume cerebral, pela migração neuronal incompleta, chegando a pesar menos de $100 \mathrm{~g}$, nas formas alobar e semilobar.

A forma alobar não possui fissura separando os dois hemisférios, que estão fundidos em uma cavidade única denominada holosfera; os giros são geralmente bem desenvolvidos, embora o curso destes não se assemelhe ao da anatomia normal de superfície. $\mathrm{O}$ aspecto posterior do cérebro lembra uma ferradura. $\mathrm{O}$ corpo caloso e a comissura anterior estão geralmente ausentes; o tronco cerebral e o cerebelo são, na maioria das vezes, normais.

A forma semilobar distingue-se da primeira, pela presença de uma fissura inter-hemisférica parcial separando a extensão posterior do hemisfério cerebral, ou seja, a fissura não se estende até a região rostral do cérebro. O padrão de giros mantém-se desorganizado.

A forma lobar é considerada a menos severa das três, apresentando uma fissura que divide virtualmente todo o cérebro, com exceção das regiões mais ventrais e rostrais dos lobos frontais. O corpo caloso pode estar bem desenvolvido e os giros assemelham-se ao padrão normal, nos casos leves. Há continuidade de tecido cerebral através da linha média e a holosfera continua sendo reconhecida ${ }^{10}$.

A citoarquitetura do córtex cerebral apresenta marcada disrupção, resultante da migração neuronal anormal. Esta hipótese é suportada pela observação de imensas heterotopias periventriculares e glioneurais de substância branca em alguns casos. Por outro lado, notou-se que, em diversos cérebros examinados, os neurônios pareciam ter alcançado o córtex. Alterações patológicas podem ser vistas em diversos outros setores do cérebro, entre eles o hipocampo, gânglios da base, tálamo, cerebelo, tronco cerebral, bulbo e trato olfatório e artérias cerebrais anterior e média. Achados menos comuns incluem encefalocele, mielomeningocele, cistos aracnóides e porencefalia ${ }^{10,25}$.

$\mathrm{O}$ tratamento envolve abordagem educacional de todos os casos, a menos que o quadro de retardo mental seja muito grave. É possível a intervenção cirúrgica naqueles com encefalocele, além da utilização de derivação para manejo da hidrocefalia. O uso de anticonvulsivantes encontra muita resistência, devido à severidade da desordem cerebral. A fisioterapia possui enorme valor ao impedir a progressão da espasticidade e de outros distúrbios motores.

A maior freqüência entre fetos abortados, em relação aos nascidos a termo, indica a pobre perspectiva de viabilidade dos conceptos acometidos pela holoprosencefalia, principalmente quando associada a anomalias cromossômicas ou na forma alobar ${ }^{18}$. Nesta categoria, a interrupção precoce da gestação constitui alternativa oferecida aos pais em alguns países ${ }^{12}$. São poucos aqueles que atingem a adolescência e vida adulta, a maioria não tem condições de estabelecer relações com o seu meio social, devido ao importante retardo neuro-psicomotor. Entretanto, os casos brandos da forma lobar podem apresentar-se fisicamente normais e com disfunções neurológicas menores, como convulsões e déficit de aprendizagem.

A amniocentese (à procura de possíveis alterações cromossômicas) e o aconselhamento genético nas gestações futuras fornecem base importante e indispensável no manejo da doença ${ }^{12}$.

\section{Conclusão}

A holoprosencefalia é uma malformação cerebral severa e rara, freqüentemente associada a patologias maternas, exposição a teratógenos e malformações cromossômicas paternas e/ou maternas, podendo ser precocemente diagnosticada no período pré-natal, através da ultra-sonografia obstétrica.

Na cidade de Pelotas (RS), a sua frequiência, que é de 0,8:10.000, foi determinada a partir deste estudo, realizado com dados obtidos durante 13 anos de monitoramento e investigação nas maternidades dos hospitais de atendimento terciário da cidade, onde nascem, por ano, aproximadamente, 5.500 crianças.

A relevância deste estudo está em determinar a freqüência dessa anomalia, tão severa, na população 
de Pelotas, bem como, relacioná-la com prováveis fatores causais, além de manter constante monitoramento que possa detectar qualquer modificação nessa frequiência e, a partir daí, investigar as causas.

\section{Agradecimentos}

Os autores agradecem a todos os participantes do Projeto de Malformações Congênitas, que visitam diariamente as cinco maternidades da cidade de Pelotas para coletar os dados dos recém-nascidos malformados e de seus controles. Além de um agradecimento em especial para Sidney Kunen e Fernando Antônio Malfatti. Sem o seu trabalho, este estudo não poderia ter sido realizado.

\section{Referências}

1. BARR Jr M, HANSON JW, CURREY K, et al.: Holoprosencephaly in infants of diabetic mothers. J Pediatr 102:565-8, 1983.

2. BLACKWELL DE, SPINNATO JÁ, HIRSCH G, et al.: Antenatal ultrasound diagnosis of holoprosencephaly. A case report. Am J Obstet Gynecol 143:848-9, 1982

3. BYRNE PJ, SILVER MM, GILBERT JM, CADERA W, TANSWELL AK: Cyclopia and congenital , cytomegalovirus infection. Am J Med Genet 28:61-5, 1987.

4. CHIANG C, LITINGTUNG Y, LEE E, et al.: Cyclopia and defective axial patterning in mice lacking Sonic hedgehog gene function. Nature 383:407-13, 1996.

5. COHEN Jr MM: Perspectives on holoprosencephaly: Part I. Epidemiology, genetics, and syndromology. Teratology 40:211-35, 1989.

6. COHEN Jr MM: Perspectives on holoprosencephaiy: Part II. Spectra, distinctions, continuities, and discontinuities. Am J Med Genet 34:271-88, 1989.

7. COOPER MK, PORTER JA, YOUNG KE, BEACHY PA: Teratogen-mediated Inhibition of target tissue response to SHH signaling. Science 280:1603-7, 1998.

8. DEMYER W: Classification of cerebral malformations. Birth Defects 7:78-93, 1971.

9. DEMYER WE, ZEMAN W, PALMER GG: The face predicts the brain: Diagnostic significance of median facial anomalies for holoprosencephaly. Pediatrics 34:256-63, 1964.

10. GOLDEN AJ: Holoprosencephaly: A defect in brain patterning. J Neuropathol Exp Neurol 57:991-9, 1998.

11. HYNES M, PORTER JA, CHIANG C, et al.: Induction of midbrain dopaminergic neurons by Sonic hedgehog. Neuron 15:35-44, 1995.

12. JONES K, LAYONS S: Padrões Reconhecíveis de Malformações Congênitas. Ed 5. São Paulo, Manole, 1998.
13. KALTER $\mathrm{H}$ : Cyclopia produced in a very early retinoic acid experiment. Teratology 46:207-8, 1992.

14. LIEM KF, TREMML G, ROELINK H, JESSEL TM: Dorsal differentiation of neural plate cells induced by BMP-mediated signals from epidermal ectoderm. Cell 82:969-79, 1995.

15. McGAHAN JP, NYBERG DA, MACK LA: Sonography of facial features of alobar and semilobar holoprosencephaly. AJR 154:143-8, 1990.

16. NELSON LH, KING M: Early diagnosis of holoprosencephaly. J Ultrasound Med 11:57, 1992.

17. OLSEN CL, HUGHES JP, YOUNGBLOOD LG, SHARPE-STIMAC M: Epidemiology of holoprosencephaly and phenotypic characteristics of affected children: New York State, 1984-1989. Am J Med Genet 73:217-26, 1997.

18. PILU G, ROMERO R, RIZZO N, JEANTY P, BOVICEI L, HOBBINS JC: Criteria for the prenatal diagnosis of holoprosencephaly. Am J Perinatol 4:41-9, 1987.

19. ROACH E, DEMYER W, CONNEALLY P, PALMER C, MERRITT A: Holoprosencephaly: Birth data, genetic and demographic analysis of 30 families. Birth Defects: Original Article Series 11:294-313, 1975.

20. ROESSLER E, MUENKE M: Holoprosencephaly: A paradigm for the complex genetics of brain development. J Inherit Metab Dis 21 :481-97, COHEN Jr MM: Perspectives on holoprosencephaiy: Part II. Spectra, distinctions, continuities, and discontinuities. Am J Med Genet 34:271-88, 1998.

21. SPEMANN $\mathrm{H}$, MANGOLD $\mathrm{H}$ : Über Induktion von embrionalanlagen durch implantation artfremder organisatoren. Arch f mikr Anat u Intw Mech 100:599638, 1924.

22. TANABE Y, JESSEL T: Diversity and pattern in the developing spinal cord. Science 274:1115-23, 1996.

23. TOTH Z, CSECSEI K, SZEIFERT G, et al.: Early prenatal diagnosis of ciclopia associated with holoprosencephaly. J Clin Ultrasound 14:550, 1986.

24. TOTH Z, CSECSEI K, SZEIFERT G, TÖRÖK O, PAPP Z: Early prenatal diagnosis of cyclopia associated with holoprosencephaly. J Clin Ultrasound 4:550-3, 1986.

25. YAKOVLEV P: Pathoarchitectonic studies of cerebral malformations: III. Arrrhinenecephalies (Holoprosencephaly). J Neuropathol Exp Neurol 18:22-55, 1959.

26. ZALEN-SPROK R, VUGT JMG, HARTEN IUH, NIEUWINT AWM, GEIJN HP: First trimester diagnosis of cyclopia and holoprosencephaly. J Ultrasound Med 14:631-3, 1995.

Original recebido em dezembro de 2004

Aceito para publicação em fevereiro de 2005

\section{Endereço para correspondência:}

Dr. Gilberto de Lima Garcias

Av. Adolfo Fetter, 1112

96083-000 - Pelotas, RS

E-mail: garcias@phoenix.ucpel.tche.br 